LA-UR-95- $\quad 4454$

TITLE:

DMSP SATELLITE DETECTIONS OF GAMMA-RAY BURSTS

AUTHOR(S):

J. Terrell, NIS-2

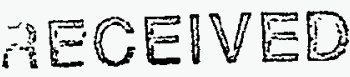

FEB 15 19ES

OSTI

P. Lee, NIS-2

R. W. Klebesadel, NIS-2

Huntsville GRB Symposium Proceddings, Huntsville, AL

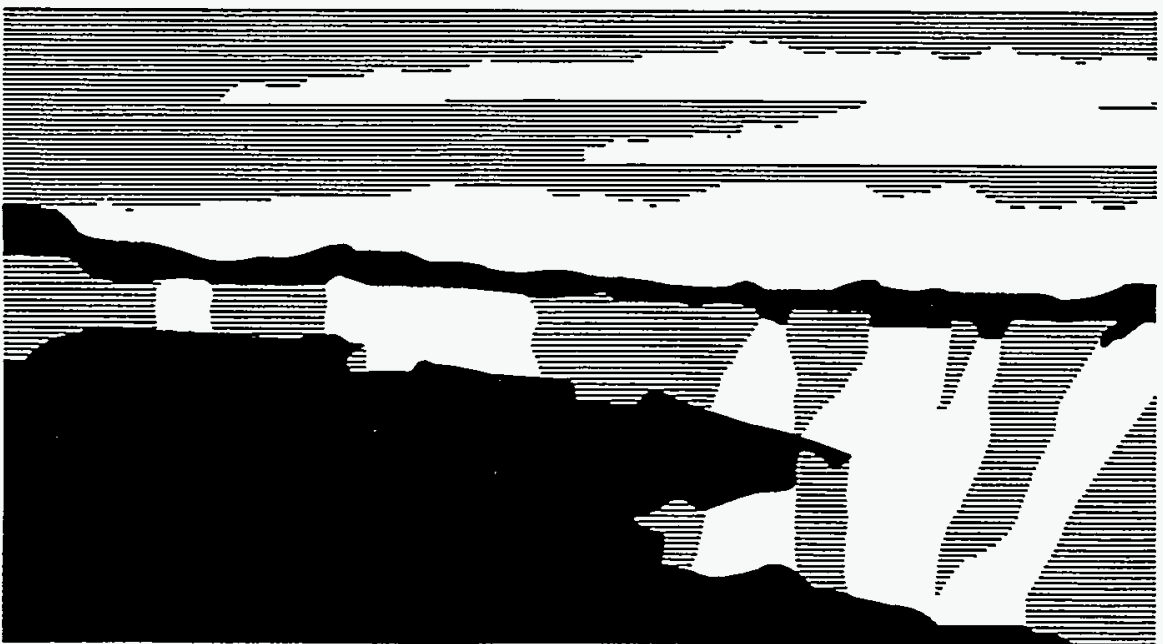

NATIONAL LABORATORY

Los Alamos National Laboratory, an aftirmative action/equal opportunity employer, is operated by the University of Califomia for the U.S. Department of Energy under contract W-7405-ENG-36. By acceptance of this article, the publisher recognizes that the U.S. Government retains a nonexclusive, royalty-free license to publish or reproduce the published form of this contribution, or to allow others to do so, for U.S. Government purposes. The Los Alamos National Laboratory requests that the publisher Identify this article as work performed under the auspices of the U.S. Department of Energy. 


\title{
DMSP Satellite Detections of Gamma-Ray Bursts
}

\author{
J. Terrell, P. Lee, and R. W. Klebesadel \\ Los Alamos National Laboratory
}

J. W. Griffee

Sandia National Laboratory

\begin{abstract}
Gamma-ray burst detectors are aboard six U. S. Air Force Defense Meteorological Satellite Program (DMSP) spacecraft, two of which are currently in use. Their $800-\mathrm{km}$ altitude orbits give a field of view to $117^{\circ}$ from the zenith. A great many bursts have been detected, usually in coincidence with detections by GRO or other satellites such as PVO or ULYSSES. The directions of the sources can be determined with considerable accuracy from such correlated observations, even when GRO/BATSE with its directional capabilities is not involved. Thus these DMSP data, especially in conjunction with other observations, should be helpful in trying to understand the true nature of gamma-ray bursts.
\end{abstract}

\section{INTRODUCTION}

Six of the DMSP spacecraft launched by the U. S. Air Force have carried gamma-ray burst detectors into orbit at $800 \mathrm{~km}$. Two of these (DMSP 12 and 13) are currently in operation, in near-polar orbits, attaining latitudes of $81^{\circ}$ with an initial launch direction of $99^{\circ}$. Each carries two gamma-ray detectors with $\sim 100 \mathrm{~cm}^{2}$ of $\mathrm{NaI}$, sensitive to gamma-rays of $50 \mathrm{keV}$ or more coming from sources within $\sim 117^{\circ}$ of the spacecraft zenith. A fuller description may be found elsewhere ${ }^{1-3}$.

\section{RESULTS}

Many gamma-ray bursts have been detected by two or more of the DMSP spacecraft. When other spacecraft have also detected these bursts, relative times of detection and fields of view can give considerable information on source location, even when no detection was made by the Compton Observatory (GRO).

Such a burst was detected by DMSP 11, 12, and 13 on 7 April 1995, and also by ULYSSES and WIND. Figure 1 shows the data from DMSP 11 for this

(C) 1996 American Institute of Physics 


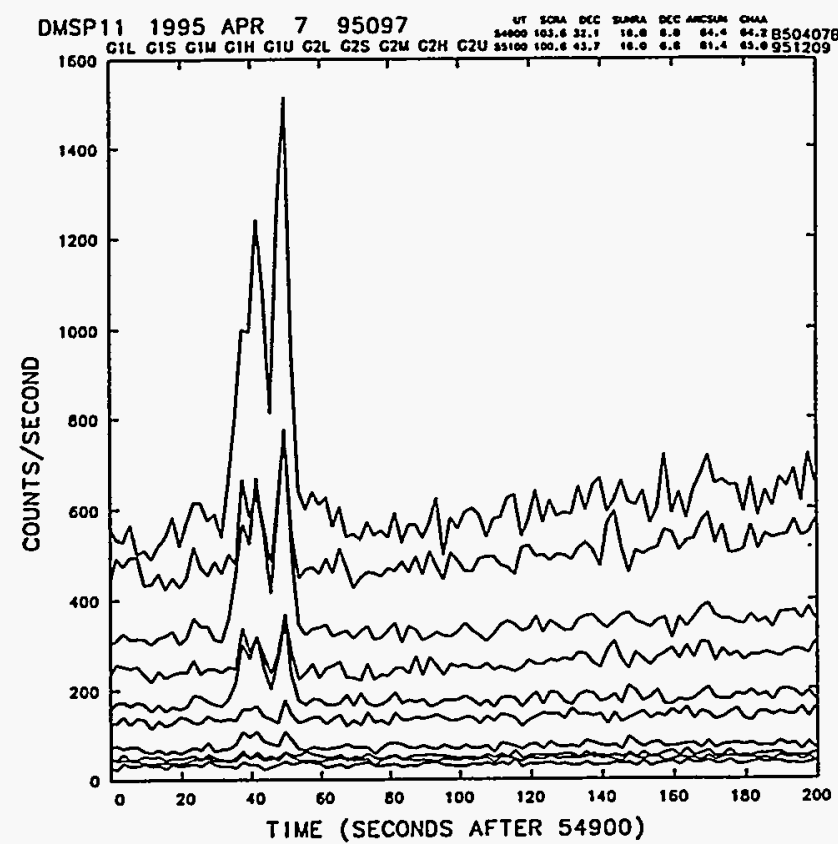

FIG. 1. DMSP 11 data for a hard gamma-ray burst on 7 April 1995.

hard burst, with gamma rays exceeding $430 \mathrm{keV}$ in both detectors (for DMSP 11 the channel thresholds are at $50,100,200,430$, and $550 \mathrm{keV}$, with cutoff at $1000 \mathrm{keV}$ ). The first counting-rate peak in the DMSP data occurred in the 2-second time channel centered on $54932 \mathrm{sec}$ UT. Direction analysis, undertaken in cooperation with other investigators, has not yet been completed for this and other events reported here.

Another hard burst, much more intense, was detected on 22 August 1995. The DMSP 12 data are shown in Figure 2. This was probably the most intense burst ever detected by DMSP satellites, with a counting rate increasing to almost 4000 counts/sec at the peak time of $13767 \mathrm{sec}$ UT. It was also detected by BATSE (GRB No. 3767), KONUS, and ULYSSES.

DMSP 13 detected a softer but interesting burst on 25 August 1995, shown in Figure 3. The first peak count at $15786 \mathrm{sec}$ UT was followed by a brief higher peak at $15864 \mathrm{sec}$, and then by a long high-energy peak extending from $\sim 15900$ to $16950 \mathrm{sec}$ UT. The NaI detectors on DMSP 13 have thresholds at $60,150,375 \mathrm{keV}$. The high-energy peak (lowest counting rates in Figure 2) corresponds to photons of energy $>6 \mathrm{MeV}$.

One of the strongest bursts ever detected by BATSE and COMPTEL ${ }^{4,5}$ was GRB No. 2831 ("Olympic"), which triggered BATSE at $82962 \mathrm{sec}$ UT on 17 February 1994. This was also detected by DMSP 10, DMSP 11, and ULYSSES. The data from DMSP 10, shown in Figure 4, indicate a curious pattern of repeated outbursts over $\sim 180$ seconds. A Fourier analysis of this 


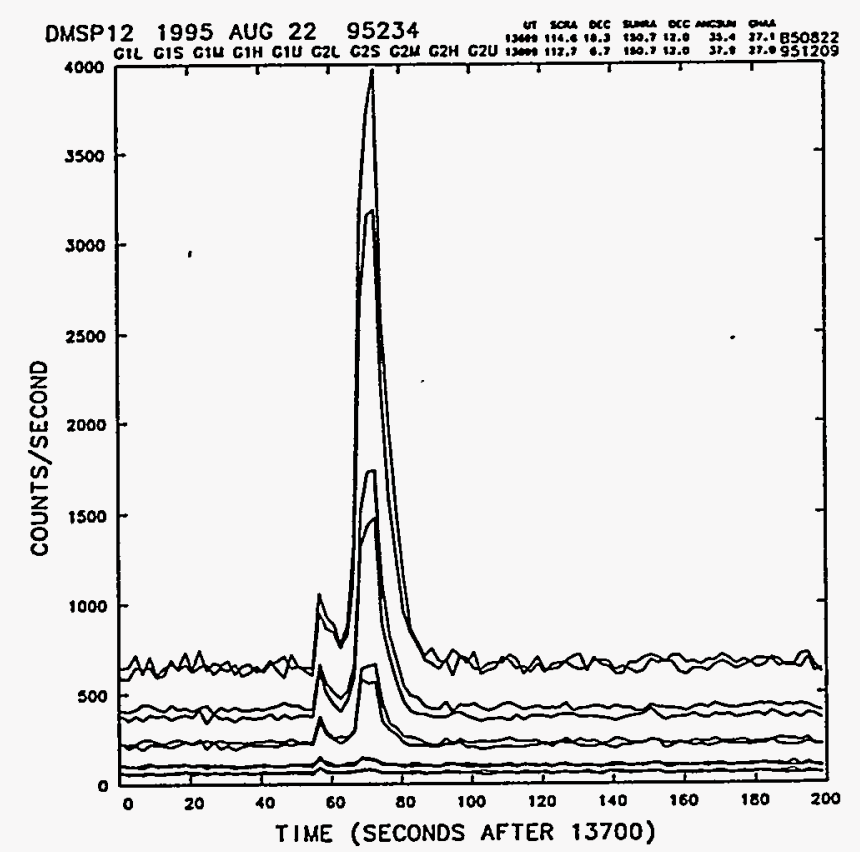

FIG. 2. DMSP 12 data for a hard and very intense gamma-ray burst on 22 August 1995.

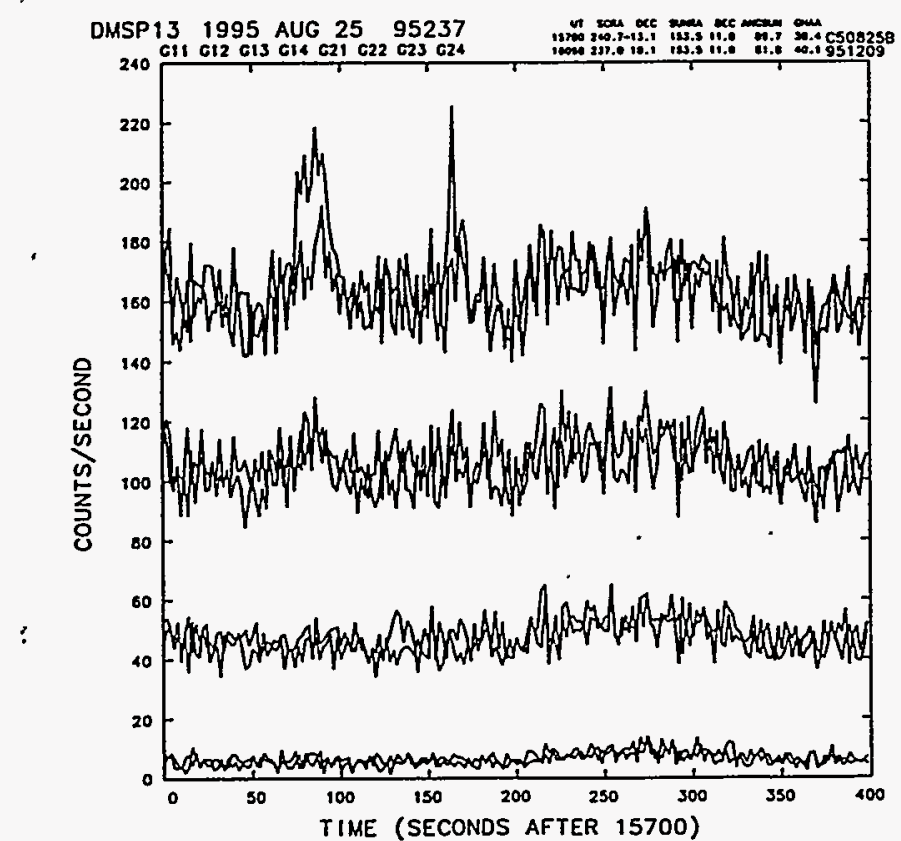

FIG. 3. DMSP 13 data for a soft gamma-ray burst followed by a very long hard afterpulse, on 22 August 1995. 


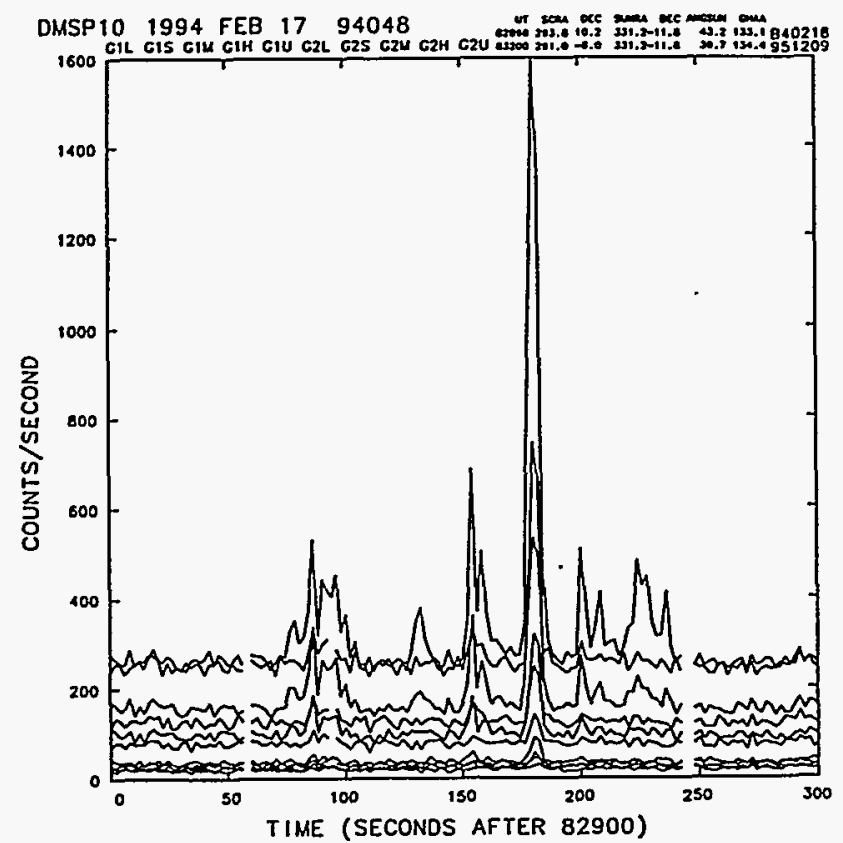

FIG. 4. DMSP 10 data for the intense gamma-ray burst of 17 February 1994.

data (that corresponding to the highest counting rates) gives some evidence of a periodicity of $\sim 24$ seconds (Figure 5); the same result is given by DMSP 11 data. Thus it is possible that this gamma-ray burst has a pulsating character reminiscent of the 5 March 1979 burst with its 8-sec periodicity ${ }^{6}$.

However, the fact that the length of the outburst is only about seven periods necessarily means that the evidence for periodicity is uncertain. Randomly occurring "shot noise" (10-sec pulses) can give a similar Fourier spectrum, with maximum power near zero frequency 7,8 . Considering that each point in Figure 5 has a standard deviation of $100 \%$, or $50 \%$ even when smoothed over 4 terms, the power spectrum gives no conclusive evidence of periodicity.

\section{CONCLUSIONS}

The DMSP spacecraft have produced a large body of data on gamma-ray bursts, representing a considerable resource for the study of these events. The data include time histories and spectral information, and directional information can be greatly enhanced by combining these observations with those of other spacecraft. They may well be of service in obtaining a fuller understanding of the origin of gamma-ray bursts..

This work was supported by NASA, by the U. S. Department of Defense, and by the U.S. Department of Energy.

\section{DISCLAIMER}

This report was prepared as an account of work sponsored by an agency of the United States Government. Neither the United States Government nor any agency thereof, nor any of their employees, makes any warranty, express or implied, or assumes any legal liability or responsibility for the accuracy, completeness, or usefulness of any information, apparatus, product, or process disclosed, or represents that its use would not infringe privately owned rights. Reference herein to any specific commercial product, process, or service by trade name, trademark, manufacturer, or otherwise does not necessarily constitute or imply its endorsement, recommendation, or favoring by the United States Government or any agency thereof. The views and opinions of authors expressed herein do not necessarily state or reflect those of the United States Government or any agency thereof. 


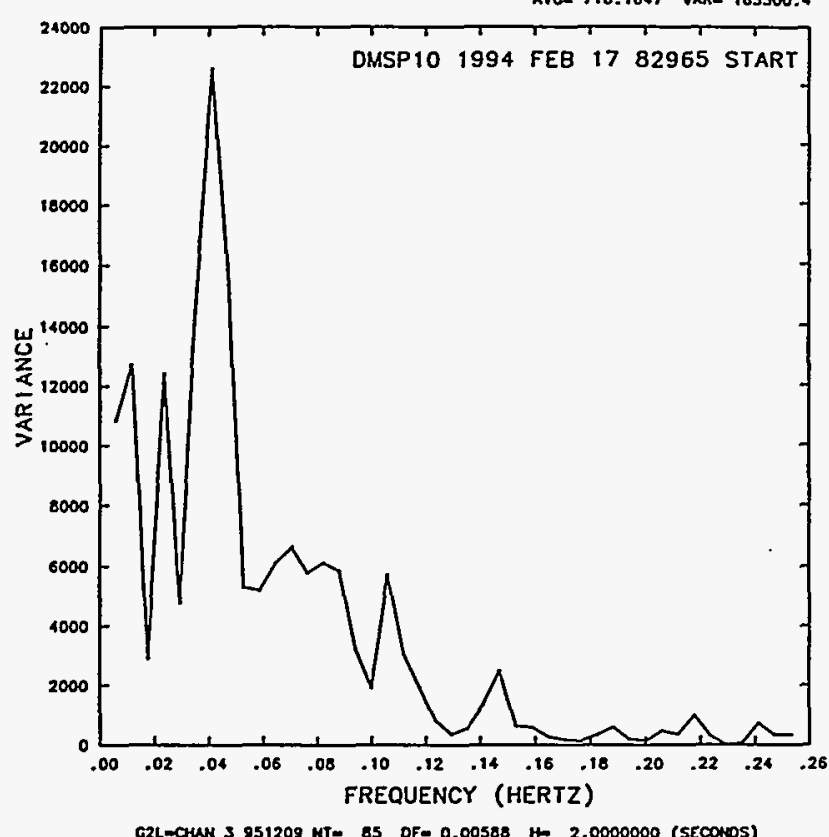

FIG. 5. Fourier power spectrum of the gamma-ray burst data in Figure 4 (DMSP 10, 17 February 1994).

\section{REFERENCES}

1. J. Terrell, P. Lee, R. W. Klebesadel, and J. W. Griffee, in Gamma-Ray Bursts, AIP Conference Proceedings 265, p.48 (AIP, New York, 1992).

2. J. Terrell, P. Lee, R. W. Klebesadel, and J. W. Griffee, in Compton Gamma-Ray Observatory, AIP Conference Proceedings 280, p.788 (AIP, New York, 1993).

3. J. Terrell, P. Lee, R. W. Klebesadel, and J. W. Griffee, in Gamma-Ray Bursts, AIP Conference Proceedings 307, p.34 (AIP, New York, 1994).

4. R. M. Kippen et al., IAU Circular No. 5937 (21 February 1994).

5. K. Hurley et al., Nature 372, 652 (1994).

6. J. Terrell, W. D. Evans, R. W. Klebesadel, and J. G. Laros, Nature 285, 383 (1980).

7. J. Terrell and K. H. Olsen, Astrophysical J. 161, 399 (1970).

8. N. J. Terrell, Astrophysical J. 174, L35 (1972). 